\title{
Periodontal Regenerative Therapy with Recombinant Human Fibroblast Growth Factor-2 and Deproteinized Bovine Bone Mineral in Patient with Chronic Periodontitis: An 18-month Follow-up Report
}

\author{
Takahiro Bizenjima $^{1)}$, Daisuke Irokawa ${ }^{2)}$, Kobun Tanaka ${ }^{3)}$, Atsushi Saito ${ }^{2)}$ \\ and Sachiyo Tomita \\ 1) Tokyo Dental College Chiba Dental Center, \\ 1-2-2 Masago, Mihama-ku, Chiba 261-8502, Japan \\ 2) Department of Periodontology, Tokyo Dental College, \\ 2-9-18 Kanda-Misakicho, Chiyoda-ku, Tokyo 101-0061, Japan \\ 3) TANAKA Dental Clinic, \\ 203, 2-24-18 Kamiosaki, Shinagawa-ku, Tokyo 141-0021, Japan
}

Received 23 June, 2020/Accepted for publication 2 November, 2020 Published Online in J-STAGE 14 May, 2021

\begin{abstract}
This report describes a case of generalized chronic periodontitis requiring periodontal regenerative therapy. The patient was a 62 -year-old man who presented with the chief complaint of gingival swelling in the molar region. An initial examination revealed that $31.6 \%$ of sites had a probing depth of $\geq 4 \mathrm{~mm}$ and $18.5 \%$ bleeding on probing. Radiographic examination revealed vertical bone resorption in \#14, 25, 26, 27, 32, 37, 45, and 47 , and horizontal resorption in other regions. Based on a clinical diagnosis of moderate chronic periodontitis, initial periodontal therapy consisting of plaque control and scaling and root planing was performed. Occlusal adjustment of premature contact sites was performed after inflammation was suppressed. Surgical periodontal therapy was subsequently performed at selected sites. Periodontal regenerative therapy using recombinant human fibroblast growth factor (rhFGF)-2 was performed on \#14, 25, 26, 32, and 37. Combination therapy with rhFGF-2 and deproteinized bovine bone mineral (DBBM) was performed on \#45 and 47. Other sites with residual periodontal pockets were treated by open flap debridement, and \#27 was extracted due to a bone defect exceeding the root apex. Progress was then reevaluated and the patient placed on supportive periodontal therapy. Periodontal regenerative therapy using rhFGF-2 in combination with DBBM resulted in an improvement in clinical parameters and vertical bone resorption. This improvement has been adequately maintained over an 18-month period. The periodontal treatment provided resulted in a marked improvement in the patient's oral healthrelated quality of life.
\end{abstract}

Key words: Chronic periodontitis - Intrabony defects -

Periodontal regenerative therapy-

Recombinant human fibroblast growth factor (rhFGF)-2-

Deproteinized bovine bone mineral 


\section{Introduction}

Periodontal regeneration has become the ideal goal in the treatment of periodontal lesions since the demonstration of the possibility of new attachment with the formation of cementum and periodontal ligament ${ }^{16)}$. Recently, various regenerative techniques have been proposed for the treatment of periodontitis with intrabony defects. In 2016, the use of $0.3 \%$ recombinant human fibroblast growth factor (rhFGF)-2 for periodontal regeneration was formally approved in Japan. Recombinant human fibroblast growth factor stimulates proliferation, differentiation, and angiogenesis in a variety of cells, and has been reported to be effective in regenerating periodontal tissue in pre-clinical models ${ }^{15,23}$. Previous in vivo studies by the present group showed that rhFGF-2 enhanced periodontal healing in an animal model ${ }^{2,6}$. The use of rhFGF-2 has been shown to be effective in periodontal regenerative therapy in clinical trials $^{9-11)}$. Furthermore, one randomized controlled clinical trial has shown that rhFGF-2 yielded a greater radiographic bone fill than enamel matrix derivative (EMD) in intrabony defects $^{9}$. However, due to its fluid consistency, rhFGF-2 appears to possess limited spacemaking potential, which, in defects with a more complicated anatomy, may not be able to prevent the collapse of a mucoperiosteal flap, thus limiting the available space for regeneration.

One comparative controlled clinical trial found that combining deproteinized bovine bone mineral (DBBM) with EMD, a biological agent, yielded greater improvement in clinical and radiographical outcomes than with EMD alone at 1 year postoperatively ${ }^{25)}$. Recently, the present research group showed that combined use of rhFGF-2 and DBBM yielded an enhanced radiographic outcome at 6 months postoperatively in the treatment of intrabony defects ${ }^{21}$. This suggests that combination therapy with rhFGF-2 and DBBM is an effective treatment modality. Here, we report a case of chronic periodontitis with intrabony defects in which periodontal regen- erative therapy with rhFGF-2 and DBBM resulted in improvements that were sustained for more than 18 months of postoperative follow-up.

\section{Case Presentation}

This case represents part of a longitudinal clinical study investigating clinical outcomes of regenerative therapy with rhFGF-2 and DBBM which was approved by the Ethics Committee of Tokyo Dental College (Approval No: 747). Written informed consent was obtained from the patient for study participation and inclusion in this report.

\section{Baseline examination}

In May 2017, a 62-year-old man visited the Clinic of Conservative Dentistry at the Tokyo Dental College Chiba Dental Center with the chief complaint of gingival swelling in the molar region. The general health of the patient was good.

The patient had first become aware of gingival swelling approximately 3 years earlier. He had received some initial periodontal treatment and had had regular check-ups every 3 months at a local dental office. In 2016, the symptoms of his periodontitis had begun to worsen, however, and as there appeared to be no subsequent improvement, his dentist referred him to our clinic for treatment. Figure 1 shows the oral view obtained at his first visit. Gingival inflammation and subgingival calculus were mostly evident in the molar region. Gingival recession was observed in \#32. Premature contact was observed in \#27 and 37.

The results of a periodontal examination (see Fig. 2) revealed that $31.6 \%$ of sites had a probing depth (PD) of $\geq 4 \mathrm{~mm}$ and $6 \%$ a PD of $\geq 6 \mathrm{~mm}$. Bleeding on probing (BOP) was observed at $18.5 \%$ of sites. The level of plaque control as assessed according to the O'Leary plaque control record (PCR $)^{18)}$ was $42 \%$. Radiographic examination (Fig. 3) revealed angular bone defects in \#14, 25, 26, 27, 32, 37, 45 , and 47 . Furcation involvement was Degree 

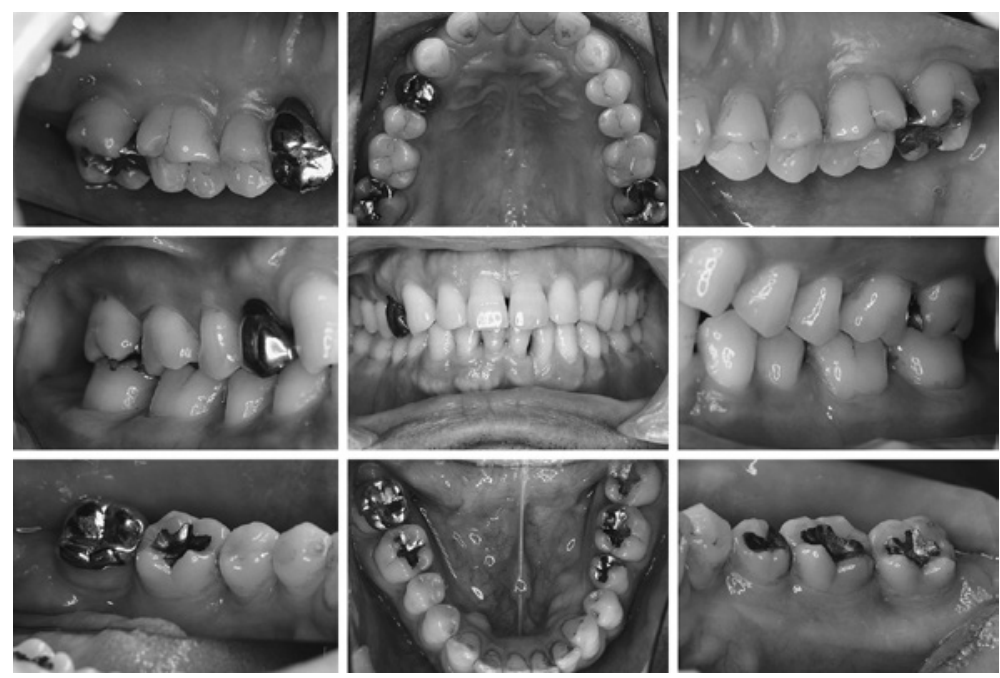

Fig. 1 Oral view at first visit

\begin{tabular}{|c|c|c|c|c|c|c|c|c|c|c|c|c|c|c|c|}
\hline \multirow{2}{*}{$\begin{array}{c}\text { Furcation } \\
\text { Bleeding on probing }\end{array}$} & $\begin{array}{l}B \\
p\end{array}$ & $\theta$ & 1 & $1+$ & + & & $1+$ & 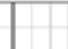 & $+1=$ & & 1 & & \multicolumn{2}{|c|}{$\because$} & I \\
\hline & B & & & & & & & & & & & & & & \\
\hline \multirow{2}{*}{ Probing Depth } & $\begin{array}{ll}8634 & \end{array}$ & \begin{tabular}{|l|l|}
4 & $3 / 4$
\end{tabular} & 4324 & \begin{tabular}{ll|l}
4 & 3
\end{tabular} & \begin{tabular}{l|l|l}
3 & 4
\end{tabular} & \begin{tabular}{l|l|}
422 & 2
\end{tabular} & \begin{tabular}{l|l}
23 & 3
\end{tabular} & $\begin{array}{l}3 \\
3\end{array}$ & 34 & 3323 & \begin{tabular}{l|l|l|}
3 & 3
\end{tabular} & & & & $\begin{array}{l}48 \\
\end{array}$ \\
\hline & P 6554 & $\begin{array}{lllll} & 3 & 4 \\
\end{array}$ & \begin{tabular}{l|l|l|l}
4 & 3 & 2 & 4 \\
\end{tabular} & 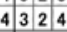 & \begin{tabular}{l|l|l}
44 & 24 \\
\end{tabular} & \begin{tabular}{l|l|l}
4 & 3 & 2 \\
\end{tabular} & \begin{tabular}{ll|l}
33 & 24 \\
\end{tabular} & 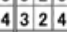 & 4423 & 332 & \begin{tabular}{l|l|l}
2 & 4 & 34 \\
\end{tabular} & \begin{tabular}{l|l}
443 \\
\end{tabular} & & $5 \longdiv { 3 3 }$ & $\begin{array}{ll}46 & 9 \\
\end{array}$ \\
\hline \multirow[t]{2}{*}{ Tooth Mobility } & 0 & 0 & 0 & 0 & 0 & 0 & 0 & 0 & 0 & 0 & 0 & 0 & & 0 & 1 \\
\hline & 7 & 6 & 5 & 4 & 3 & 2 & 1 & 1 & 2 & 3 & 4 & 5 & & 6 & 7 \\
\hline \multirow[t]{2}{*}{ Tooth Mobility } & 0 & 0 & 0 & 0 & 0 & 0 & 0 & 0 & 0 & 0 & 0 & 0 & & 0 & 0 \\
\hline & 4436 & 6422 & \begin{tabular}{l|l|l}
25 & 34 \\
\end{tabular} & $\begin{array}{lll}4 & 4 & 2 \\
\end{array}$ & \begin{tabular}{l|l|l}
32 & 22 \\
\end{tabular} & \begin{tabular}{l|l|l}
2 & 322 \\
\end{tabular} & \begin{tabular}{ll|l}
22 & 23 \\
\end{tabular} & 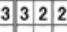 & 2422 & 2222 & \begin{tabular}{l|l|l}
2 & 2 & 24 \\
\end{tabular} & & 32 & 233 & \begin{tabular}{ll|l}
3 & 3 & 3 \\
\end{tabular} \\
\hline Probing Depth & $B^{4}$ & 7423 & \begin{tabular}{l|l|l}
3 & 5 & 24 \\
\end{tabular} & \begin{tabular}{l|l|l}
4 & 2 & 2
\end{tabular} & $\begin{array}{llll}2 & 3 & 2\end{array}$ & & \begin{tabular}{l|l|l|l|l|l|l|l|l}
3 & 2 & 2
\end{tabular} & 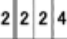 & $\begin{array}{lll}3 & 3 \\
\end{array}$ & \begin{tabular}{l|l|l}
3 & 3 & 2 \\
\end{tabular} & \begin{tabular}{l|l|l}
3 & 4 & 2 \\
\end{tabular} & & \begin{tabular}{|l|l}
4 & 3
\end{tabular} & 323 & 523 \\
\hline \multicolumn{16}{|c|}{ 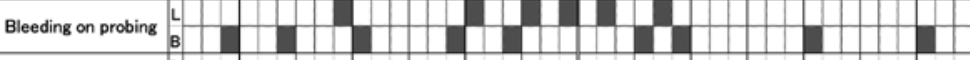 } \\
\hline Furcation & L & & & & & & & & & & & & & & \\
\hline & & & & & & & & & & & & & & & \\
\hline
\end{tabular}

Fig. 2 Periodontal examination at first visit

1 for \#27. As a measure of patient-reported outcome, oral health-related quality of life (QoL) was assessed using an oral healthrelated QoL instrument (OHRQL) ${ }^{22)}$. The total OHRQL score was 19.

\section{Diagnosis}

The clinical diagnosis was Stage III, Grade B generalized chronic periodontitis ${ }^{1,19}$. A treatment plan was presented to the patient and his consent to the proposed plan obtained.

\section{Clinical Procedures and Outcomes}

\section{Treatment plan}

1) Initial periodontal therapy

This comprised oral hygiene instruction, quadrant scaling and root planing (SRP), root canal treatment in \#27, and occlusal adjustment for \#27 and 37.

2) Reevaluation

3) Periodontal surgery

Periodontal surgery for sites with a PD of $\geq 4 \mathrm{~mm}$. Periodontal regenerative therapy with rhFGF-2 for \#14, 25, 26, 27, 32, 37, 45, and 47 . 


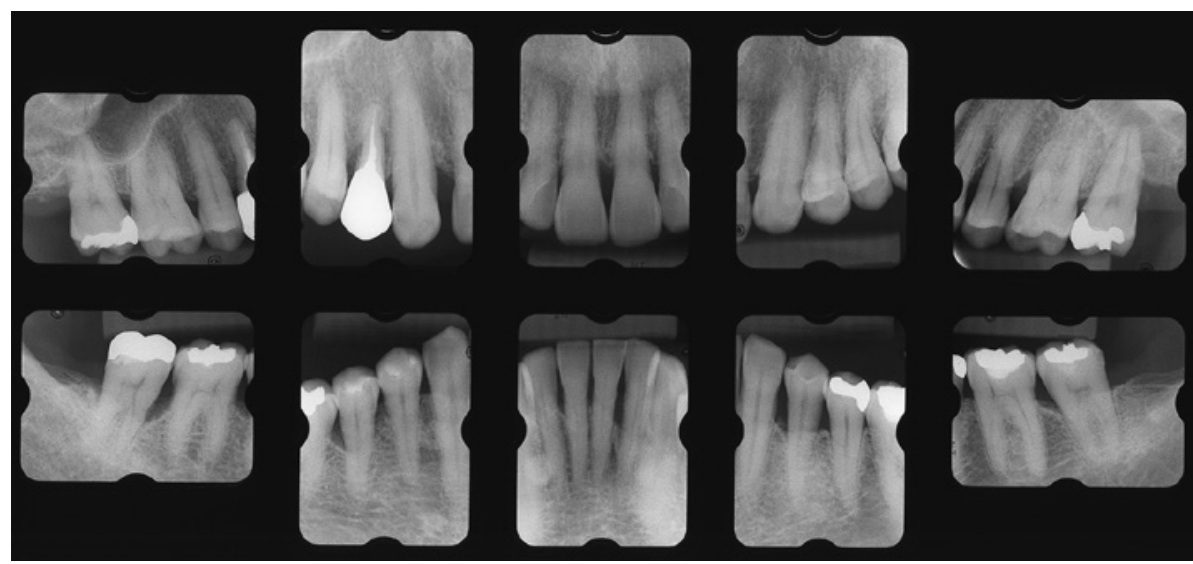

Fig. 3 Radiographic view at first visit

4) Reevaluation

5) Treatment for recovery of oral function Placement of full metal crown for \#27.

6) Reevaluation

7) Supportive periodontal therapy (SPT) or maintenance

\section{Treatment process}

An outline of the treatment process is shown in Table 1.

1) Initial periodontal therapy

After obtaining informed consent for the proposed treatment plan, instruction was given on maintaining oral hygiene and quadrant SRP performed. Root canal treatment was performed for \#27. Occlusal adjustment was implemented for \#27 and 37.

2) Reevaluation

Subsequent reevaluation revealed a reduction in the PCR score to $19 \%$ and a decrease to $15.3 \%$ and $4.8 \%$ for sites with a PD of $\geq 4$ $\mathrm{mm}$ and $6 \mathrm{~mm}$, respectively. The OHRQL total score was 13. Closed pockets ${ }^{24)}$ were observed in $18.7 \%$ of the teeth and BOP in $13.1 \%$. There results were judged to be "insufficient" according to the criteria for the success of non-surgical periodontal therapy ${ }^{8}$.

3) Periodontal surgery

Based on the results of the reevaluation, the need for periodontal surgery was explained and informed consent for its implementation obtained. Regenerative therapy with rhFGF-2 [REGROTH ${ }^{\circledR}$ Dental Kit, $600 \mu \mathrm{g}$ in hydroxypropyl cellulose, Kaken Pharmaceutical, Tokyo, Japan] and DBBM (Geistlich Bio-Oss $^{\circledast}$, 0.25-1.0 mm granules, Geistlich Pharma AG, Wolhusen, Switzerland) was then performed on \#45 and 47 for deep intrabony defects (Fig. 4). Subsequently, regenerative therapy with rhFGF-2 was performed on \#14, 25, 26, 32, and 37. Open flap debridement was implemented for \#15, 16, 17, 31, 33, 35, $36,41,42$, and 43 to reduce periodontal pockets. Intraoperatively, \#27 had to be extracted due to a bone defect exceeding the root apex.

4) Reevaluation

On reevaluation, gingival inflammation showed an improvement. Sites with a PD of $\geq 4 \mathrm{~mm}$ and BOP had disappeared.

5) Treatment for recovery of oral function

The patient complained of poor esthetics and requested a new prosthesis. A CAD/CAM resin crown was then placed on \#14.

6) Reevaluation

On reevaluation, an improvement was observed in gingival inflammation and PD (Fig. 5 and 6). The patient's level of plaque control was good (PCR <20\%). Various levels of improvement were observed radiographically at those sites selected for regenerative therapy (Fig. 7). The periodontal conditions were judged to be stable, and the patient was placed in a recall system for SPT. 
Table 1 Treatment process

\begin{tabular}{|c|c|}
\hline \multirow[t]{5}{*}{ May 2017} & Initial periodontal therapy \\
\hline & $\cdot$ Plaque control \\
\hline & · Quadrant SRP \\
\hline & - Occlusal adjustment $(\# 27,37)$ \\
\hline & $\cdot$ Root canal treatment (\#27) \\
\hline \multirow[t]{6}{*}{ September 2017} & (Reevaluation) \\
\hline & Surgical periodontal therapy \\
\hline & - Open flap debridement (\#15, 16, 17, 31, 33, 35, 36, 41, 42, 43) \\
\hline & $\cdot$ Regenerative therapy with rhFGF-2 (\#14, 25, 26, 32, 37) \\
\hline & · Regenerative therapy with rhFGF-2 + DBBM $(\# 45,47)$ \\
\hline & $\cdot$ Extraction $(\# 27)$ \\
\hline \multirow[t]{3}{*}{ May 2018} & (Reevaluation) \\
\hline & Treatment for recovery of oral function \\
\hline & - Crown restoration $(\# 14)$ \\
\hline \multirow{4}{*}{$\begin{array}{l}\text { September } 2018 \\
\text { to present }\end{array}$} & (Reevaluation) \\
\hline & Supportive periodontal therapy \\
\hline & $\cdot$ Oral hygiene instruction \\
\hline & - Professional tooth cleaning \\
\hline
\end{tabular}

SRP: scaling and root planing
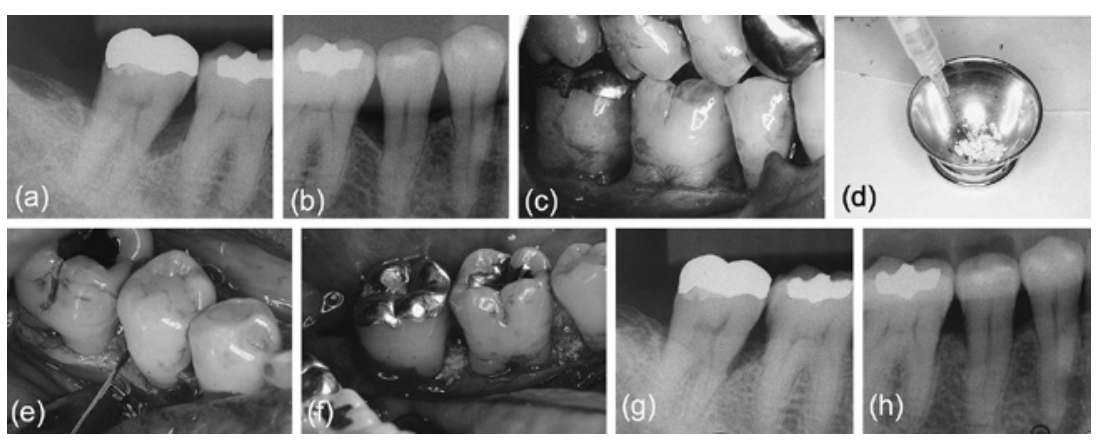

Fig. 4 Periodontal regenerative therapy with rhFGF-2 and DBBM $(\# 45,47)$

(a) (b) Preoperative radiograph. (c) Intra-operative view. (d) rhFGF-2 mixed with DBBM. (e) After debridement and rinsing, filled with rhFGF-2. (f) Defects were completely filled with rhFGF-2 and DBBM. Care was taken not to overfill defects. $(\mathrm{g})(\mathrm{h}) 18$ months of SPT.

\section{7) $\mathrm{SPT}$}

Over 18 months of SPT, pockets with a PD of $4 \mathrm{~mm}$ were found in \#17 (Fig. 9), but the periodontal condition remained stable in most of the teeth (Fig. 8 and 9). A 3.1-mm gain in mean clinical attachment level (CAL) was observed in the teeth treated with rhFGF-2
(Fig. 11). In \#45 and 47, combined treatment with rhFGF-2 and DBBM yielded CAL gains of $3.0 \mathrm{~mm}$ and $4.0 \mathrm{~mm}$, respectively (Fig. 12). Distinct radiographic bone fill was observed in the teeth treated with the combination of rhFGF-2 and DBBM (Fig. 4 and 10). The total OHRQL score was 6 , indicating an improve- 

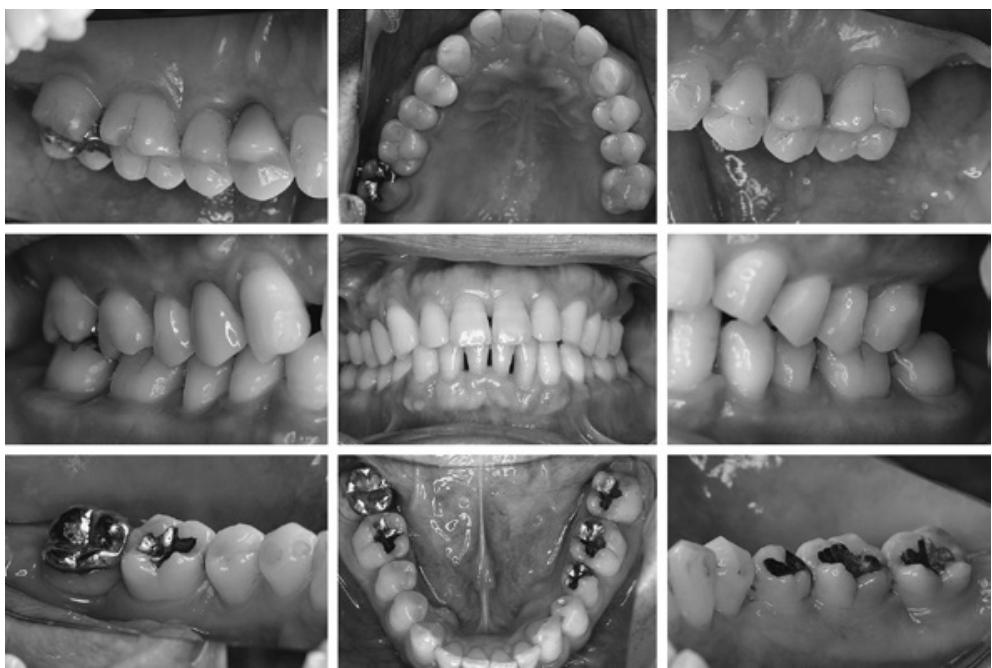

Fig. 5 Oral view at start of SPT

\begin{tabular}{|c|c|c|c|c|c|c|c|c|c|c|c|c|c|c|c|}
\hline Furcation & B & & & & & & & & & & & & & & \\
\hline Bleeding on orobing & & & & & & & & & & & & & & & \\
\hline Bleeding on probing & & & & & & & & & & & & & & & \\
\hline Probing Depth & & 323 & $\begin{array}{lll}2 & 23 \\
\end{array}$ & & 23 & $\begin{array}{ll}322 \\
\end{array}$ & 222 & 222 & $\begin{array}{llll}3 & 2 & 3\end{array}$ & 222 & $\begin{array}{ll}2 & 223 \\
\end{array}$ & & & $\begin{array}{llll}3 & 2 & 2 & 3\end{array}$ & \\
\hline Tooth Mobility & $\begin{array}{c}3 \cdot 3 \cdot 2 \cdot 3 \\
0\end{array}$ & 322 & 223 & 322 & 23 & $\begin{array}{ll}32 & 2 \\
& \end{array}$ & 323 & 322 & 2322 & 222 & $\begin{array}{ll}2 & 222 \\
2\end{array}$ & $\begin{array}{ll}32 & 23 \\
& \end{array}$ & 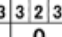 & 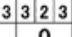 & \\
\hline & & & & & & & & & & & & & & & \\
\hline & 7 & 6 & 5 & 4 & 4 & 3 & 2 & 1 & 1 & 2 & 3 & 4 & 5 & 6 & 7 \\
\hline Tooth Mobility & 0 & 0 & 0 & 0 & 0 & 0 & 0 & 0 & 0 & 0 & 0 & 0 & 0 & 0 & 0 \\
\hline & $\begin{array}{lll}32 & 3 \\
\end{array}$ & 322 & 223 & & 22 & \begin{tabular}{l|l}
222 \\
\end{tabular} & \begin{tabular}{l|l}
32 & 22 \\
\end{tabular} & 222 & 2222 & 222 & 2222 & 223 & \begin{tabular}{ll|l}
3 & 3 & 2 \\
\end{tabular} & 3323 & 323 \\
\hline Probing Depth & 332 & 223 & \begin{tabular}{l|l|l}
2 & 2 & 3 \\
\end{tabular} & & & $\begin{array}{llll}32 & 3\end{array}$ & 222 & 222 & 2222 & 222 & 2222 & 222 & 2222 & & 224 \\
\hline Bleeding on probing & t & & & & & & & & & & & & & & \\
\hline Bleeding on probing & & & & & & & & & & & & & & & \\
\hline Furcation & L & - & & & & & & & & & & & & & \\
\hline
\end{tabular}

Fig. 6 Periodontal examination at start of SPT

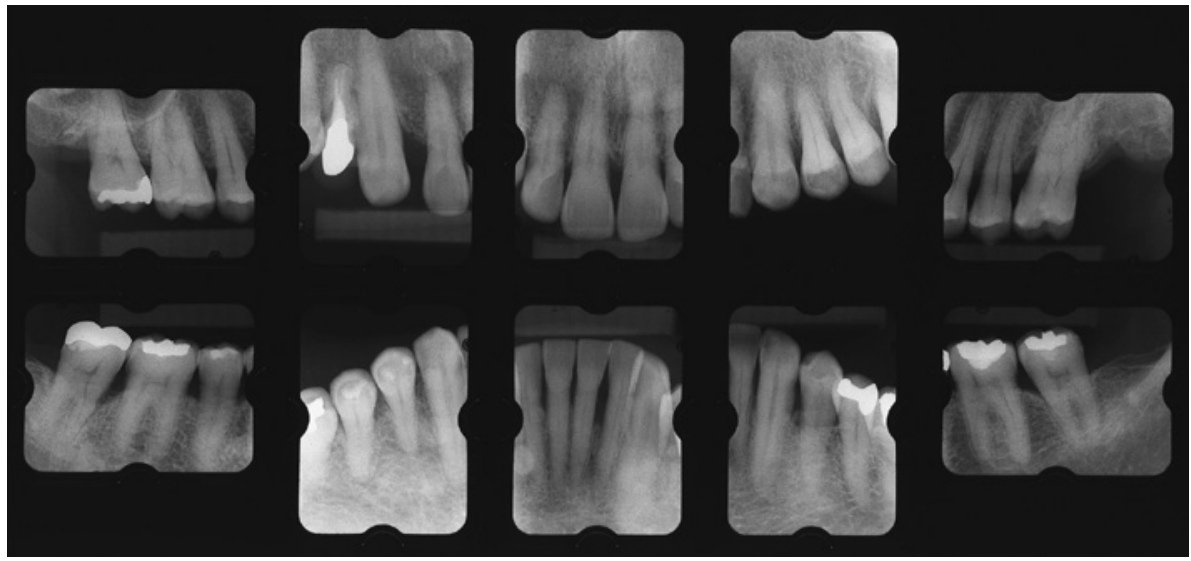

Fig. 7 Radiographic view at start of SPT 

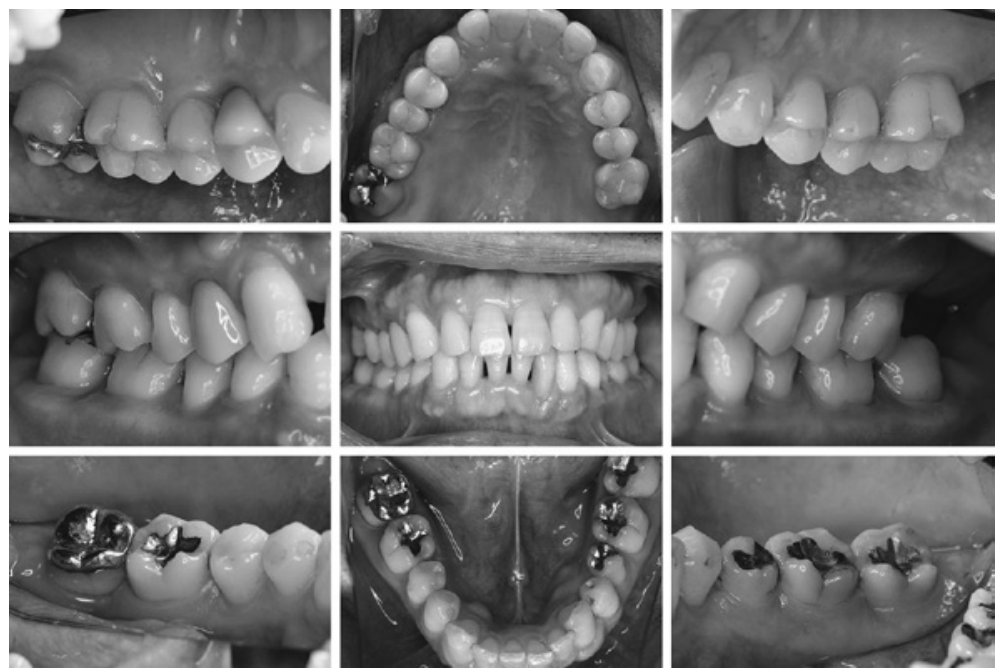

Fig. 8 Oral view at 18 months of SPT

\begin{tabular}{|c|c|c|c|c|c|c|c|c|c|c|c|c|c|c|c|c|}
\hline Furcation & B & & & & & & & & & & & & & & & \\
\hline 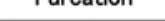 & P] & & & & & & & & & & & & & & & \\
\hline Bleeding on probing & B & & & & & & & & & & & & & & & \\
\hline 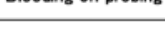 & 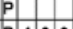 & & & & & & & & & & & & & & & \\
\hline Probing Depth & (8) 4322 & $\begin{array}{ll}3 & 23 \\
& 2\end{array}$ & 22 & $\begin{array}{l}332 \\
3\end{array}$ & & \begin{tabular}{ll|l}
32 & 2 \\
\end{tabular} & & & 222 & \begin{tabular}{|l|l|l|}
3 & 2 & 3 \\
\end{tabular} & $\begin{array}{ll}22 & 22 \\
\end{array}$ & 22223 & \begin{tabular}{l|l|l|l}
3 & 2 & 2 & 3 \\
\end{tabular} & \begin{tabular}{l|l|l|l}
3 & 2 & 2 & 3 \\
\end{tabular} & \begin{tabular}{l|l|l|l|}
3 & 2 & 2 & 3 \\
\end{tabular} & \\
\hline Tooth Mobility & $\frac{13 / 2 / 3}{0}$ & $\begin{array}{l}3 / 2 \\
\\
0\end{array}$ & $\frac{2}{2}|2|$ & $32 \mid 2$ & \begin{tabular}{ll|l}
2 & 2 \\
\end{tabular} & $\frac{3 \cdot 2 \mid 2}{0}$ & $\frac{3 \mid 2}{0}$ & & $\frac{22}{2}$ & \begin{tabular}{|c|c|c|}
$3 / 2$ & 2 \\
0
\end{tabular} & $\begin{array}{c}22222 \\
0\end{array}$ & \begin{tabular}{rl|l|l|l|l|}
2 & 2 & 2 \\
0
\end{tabular} & $\begin{array}{c}2|3| 2 \mid 3 \\
0\end{array}$ & $\begin{array}{r}3|3| 2 \mid 3 \\
0\end{array}$ & 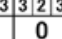 & \\
\hline & 7 & 6 & 5 & & 4 & 3 & 2 & 2 & 1 & 1 & 2 & 3 & 4 & 5 & 6 & 7 \\
\hline Tooth Mobility & 0 & 0 & 0 & & 0 & 0 & 0 & 0 & 0 & 0 & 0 & 0 & 0 & 0 & 0 & 0 \\
\hline & $\begin{array}{ll}323 \\
\end{array}$ & \begin{tabular}{|l|l|}
3222 \\
\end{tabular} & 22 & & 22 & $\begin{array}{ll}222 \\
\end{array}$ & & 222 & \begin{tabular}{|l|l|}
222 \\
\end{tabular} & \begin{tabular}{|l|l|}
222 \\
\end{tabular} & $\begin{array}{ll}222 \\
\end{array}$ & \begin{tabular}{l|l|l|}
2 & 222 \\
\end{tabular} & \begin{tabular}{|l|l|l|}
2 & 2 & 23 \\
\end{tabular} & \begin{tabular}{l|l|l}
3 & 3 & 2 \\
\end{tabular} & \begin{tabular}{l|l|l}
3 & 3 & 2 \\
\end{tabular} & \begin{tabular}{|l|l|l|}
3 & 2 & 3 \\
\end{tabular} \\
\hline Probing Depth & \begin{tabular}{l|l|l}
3 & 23
\end{tabular} & \begin{tabular}{|l|l|l|l|}
2 & 2 & 3
\end{tabular} & \begin{tabular}{|l|l|l|}
2 & 2
\end{tabular} & & 23 & \begin{tabular}{l|l}
3 & 2 \\
\end{tabular} & & \begin{tabular}{l|l|l}
2 & 2 & 2
\end{tabular} & \begin{tabular}{ll|l|l|}
2 & 2 &
\end{tabular} & 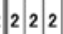 & 222 & $2|2| 2 \mid$ & \begin{tabular}{l|l|l}
2 & 2 & 2
\end{tabular} & $2 \mid$\begin{tabular}{l|l}
2 & 2 \\
2
\end{tabular} & 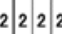 & 2223 \\
\hline Rlandiper on nmbing & 니 & & & & & & & & & & & & & & & \\
\hline Bleeding on pro & B & & & & & & & & & & & & & & & \\
\hline Furcation & 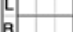 & 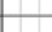 & & & & & & & & & & & & & & \\
\hline & & & & & & & & & & & & & & & & \\
\hline
\end{tabular}

Fig. 9 Periodontal examination at 18 months of SPT

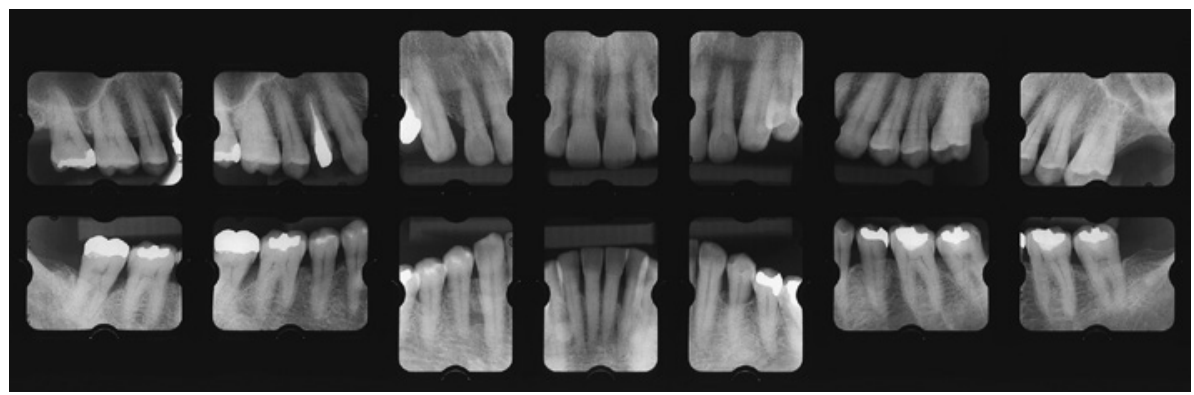

Fig. 10 Radiographic view at 18 months of SPT 


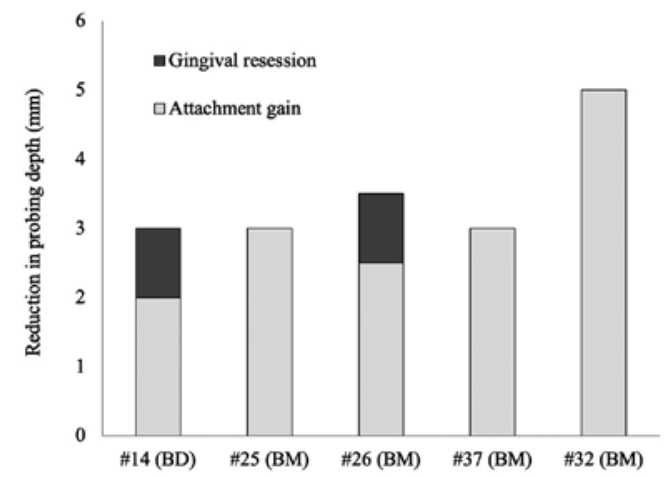

Fig. 11 Contribution of gingival recession and attachment gain to reduction in probing depth with rhFGF-2

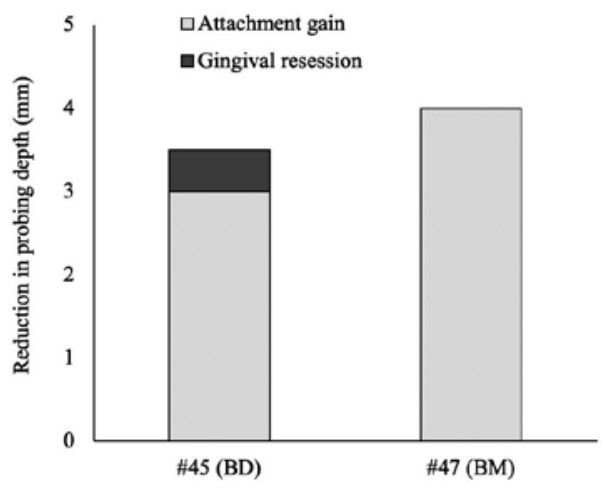

Fig. 12 Contribution of gingival recession and attachment gain to reduction in probing depth with combination of rhFGF-2 and DBBM

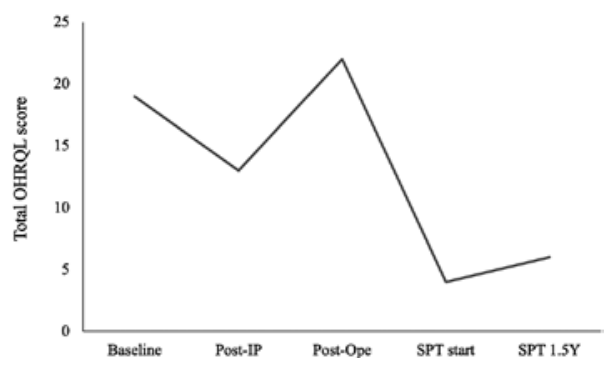

Fig. 13 Change in total OHRQL score during treatment

ment in QoL from at first visit (Fig. 13). Occlusion was frequently examined to control occlusal trauma during SPT.

\section{Discussion}

Application of rhFGF-2 has been reported to greatly improve clinical outcomes and bone loss $^{9-11)}$. In the present case (SPT, 18 months), treatment of periodontal defects with rhFGF-2 alone yielded an improvement in PD and clinically relevant CAL gain at 18 months postoperatively (Fig. 11). Kitamura $e t$ al. reported a mean gain in CAL of $2.7 \mathrm{~mm}$ at 9 months following rhFGF-2 therapy ${ }^{9}$. The 18-month results in the present case are in agreement with this earlier finding. However, periodontal regeneration in large circumfer- ential defects without bony walls is considered difficult because it may not be possible to preserve space for regeneration of periodontal tissue or retain the blood clot to promote healing. According to an evidence-based decision tree proposed by Reynolds et al.$^{20)}$, the combined use of supportive or filling materials is recommended in treating wide defects and/or non-contained defects ${ }^{20}$. This suggests that it is effective to use bone substitutes as a scaffold for regeneration.

There are multiple opinions regarding the effect of bone substitutes in combination regenerative therapy. According to a clinical practice guideline issued by the Japanese Society of Periodontology ${ }^{7}$, there is no clear evidence of an additional effect when a bone graft is applied in combination with guided tissue regeneration or EMD. This indicates 
the need to carefully consider different combinations of regenerative therapies, such as application of growth factor and bone substitutes. In one previous report, FGF-2 used in combination with beta-tricalcium phosphate $(\beta$ TCP $)$ yielded a significant increase in new bone and cementum formation in comparison with in an FGF-2-alone group in a dog model $^{17)}$. In one multicenter randomized controlled trial evaluating the treatment of intrabony periodontal defects, rhFGF-2 used in combination with $\beta$-TCP improved clinical parameters at 6 months in comparison with $\beta$-TCP alone ${ }^{3)}$. The reported CAL gain with treatment comprising rhFGF-2 in combination with $\beta$-TCP was $3.0 \mathrm{~mm}$ at 6 months postoperatively. Saito et al. reported a mean gain in CAL of $3.16 \mathrm{~mm}$ at 6 months following rhFGF-2 and DBBM therapy ${ }^{211}$. In the present case, treatment of periodontal defects with rhFGF-2 and DBBM yielded CAL gains of 3.0 $\mathrm{mm}$ and $4.0 \mathrm{~mm}$, respectively at 18 months postoperatively (Fig. 12). This is consistent with findings from previous studies. However, caution has to be exercised when comparing these results, as there may have been differences in the initial probing depth or attachment level. In the present case, increases in radiopacity were confirmed at 3 months postoperatively after treatment with the combination of rhFGF-2 and DBBM, and further improvement was observed at 18 months (Fig. 4). One previous study showed that DBBM particles were still present after 4 years 6 months postoperatively with no clear signs of resorption $^{5)}$. To prevent complications, it is necessary to continue long-term observation of change in radiopacity.

In the present case, the OHRQL score showed an improvement after initial periodontal therapy, a finding consistent with those in our own previous reports ${ }^{14}$. We believe that this was due to the removal of the chief complaint and improvement of the oral environment with initial periodontal treatment. The OHRQL score worsened after surgical treatment compared with at first visit, however. This may have been due to the patient experiencing postoperative discom- fort, which might have included pain, swelling, or tooth sensitivity. We believe that this was not due to combined use of rhFGF-2 and DBBM. At the start of SPT, the OHRQL score appeared to improve compared to with that after surgical treatment. We speculate that resolution of discomfort after surgical treatment and recovery of oral function through the wearing of prosthetic appliances may have contributed to this improvement in QoL. In the present case, the OHRQL score remained stable during SPT.

The risk during the maintenance phase was determined to be low according to the Periodontal Risk Assessment ${ }^{13)}$. Several sites were found to be positive for BOP, however. Sites recognized as having BOP during SPT indicate a higher probability of periodontitis progression $^{12)}$. Cugini et al. reported that maintenance scaling appeared to be important in sustaining post-therapy decreases in mean levels of subgingival microbiota over a prolonged period of time ${ }^{4}$. In consideration of these earlier reports, the present patient was placed on a 3-month recall schedule for SPT, during which the level of oral hygiene was also checked.

In summary, periodontal treatment including regenerative therapy with rhFGF-2 and DBBM yielded a marked improvement in clinical parameters and radiographic bone fill. Careful SPT is scheduled to be continued.

\section{Acknowledgements}

We report no conflict of interest with regards to this case report.

\section{References}

1) Armitage GC (1999) Development of a classification system for periodontal diseases and conditions. Ann Periodontol 4:1-6.

2) Bizenjima $T$, Seshima $F$, Ishizuka $Y$, Takeuchi $T$, Kinumatsu T, Saito A (2015) Fibroblast growth factor-2 promotes healing of surgically created 
periodontal defects in rats with early, streptozotocin-induced diabetes via increasing cell proliferation and regulating angiogenesis. J Clin Periodontol 42:62-71.

3) Cochran DL, Oh T-J, Mills MP, Clem DS, McClain PK, Schallhorn RA, McGuire MK, Scheyer ET, Giannobile WV, Reddy MS, AbouArraj RV, Vassilopoulos PJ, Genco WV, Geurs NC, Takemura A (2016) A randomized clinical trial evaluating rh-FGF-2/ $\beta$-TCP in periodontal defects. J Dent Res 95:523-530.

4) Cugini MA, Haffajee AD, Smith C, Kent RL Jr, Socransky SS (2000) The effect of scaling and root planning on the clinical and micribiological parameters of periodontal disease: 12-month results. J Clin Periodontal 27:30-36.

5) Ewers R, Goriwoda W, Schopper C, Moser D, Spassova E (2004) Histologic findings at augmented bone areas supplied with two different bone substitute materials combined with sinus floor lifting. Clin Oral Implants Res 15: 96-100.

6) Ishii Y, Fujita T, Okubo N, Ota M, Yamada S, Saito A (2013) Effect of basic fibroblast growth factor (FGF-2) in combination with beta tricalcium phosphate on root coverage in dog. Acta Odontol Scand 71:325-332.

7) Japanese Society of Periodontology (2017) JSP Clinical Practice Guideline for the Periodontal Treatment, 2015, p.53, Ishiyaku Publishers, Tokyo, Japan.

8) Jönsson B, Öhrn K, Lindberg P, Oscarson N (2010) Evaluation of an individually tailored oral health educational programme on periodontal health. J Clin Periodontol 37: 912-919.

9) Kitamura M, Akamatsu M, Kawanami M, Furuichi Y, Fujii T, Mori M, Kunimatsu K, Shimauchi H, Ogata Y, Yamamoto M, Nakagawa T, Sato S, Ito K, Ogasawara T, Izumi Y, Gomi K, Yamazaki K, Yoshie H, Fukuda M, Noguchi T, Takashiba S, Kurihara H, Nagata T, Hamachi T, Maeda K, Yokota M, Sakagami R, Hara Y, Noguchi K, Furuuchi T, Sasano T, Imai E, Ohmae M, Koizumi H, Watanuki M, Murakami S (2016) Randomized placebocontrolled and controlled non-inferiority phase III trials comparing trafermin, a recombinant human fibroblast growth factor 2 , and enamel matrix derivative in periodontal regeneration in intrabony defects. J Bone Miner Res 31:806-814.

10) Kitamura M, Akamatsu M, Machigashira M, Hara Y, Sakagami R, Hirofuji T, Hamachi T, Maeda K, Yokota M, Kido J, Nagata T, Kurihara H, Takashiba S, Sibutani T, Fukuda M, Noguchi T, Yamazaki K, Yoshie H, Ioroi K, Arai T, Nakagawa T, Ito K, Oda S, Izumi Y, Ogata Y,
Yamada S, Shimauchi H, Kunimatsu K, Kawanami M, Fujii T, Furuichi Y, Furuuchi T, Sasano T, Imai E, Omae M, Yamada S, Watanuki M, Murakami S (2011) FGF-2 stimulates periodontal regeneration: results of a multi-center randomized clinical trial. J Dent Res 90:35-40.

11) Kitamura M, Nakashima K, Kowashi Y, Fujii T, Shimauchi H, Sasano T, Furuuchi T, Fukuda M, Noguchi T, Shibutani T, Iwayama Y, Takashiba S, Kurihara H, Ninomiya M, Kido J, Nagata T, Hamachi T, Maeda K, Hara Y, Izumi Y, Hirofuji T, Imai E, Omae M, Watanuki M, Murakami S (2008) Periodontal tissue regeneration using fibroblast growth factor-2: randomized controlled phase II clinical trial. PLOS ONE 3:e2611.

12) Lang NP, Joss A, Orsanic T, Gusberti FA, Siegrist BE (1986) Bleeding on probing. A predictor for the progression of periodontal disease? J Clin Periodontol 13:590-596.

13) Lang NP, Tonetti MS (2003) Periodontal risk assessment (PRA) for patients in supportive periodontal therapy (SPT). Oral Health Prev Dent 1:7-16.

14) Makino-Oi A, Ishii $Y$, Hoshino T, Okubo N, Sugito H, Hosaka Y, Fukaya C, Nakagawa T, Saito A (2016) Effect of periodontal surgery on oral health-related quality of life in patients who have completed initial periodontal therapy. J Periodontal Res 51:212-220.

15) Murakami S, Takayama S, Kitamura M, Shimabukuro Y, Yanagi K, Ikezawa K, Saho T, Nozaki T, Okada H (2003) Recombinant human basic fibroblast growth factor (bFGF) stimulates periodontal regeneration in class II furcation defects created in beagle dogs. J Periodontal Res 38:97-103.

16) Nyman S, Lindhe J, Karring $T$, Rylander $H$ (1982) New attachment following surgical treatment of human periodontal disease. J Clin Periodontol 9:290-296.

17) Oi Y, Ota M, Yamamoto S, Shibukawa Y, Yamada S (2009) $\beta$-tricalcium phosphate and basic fibroblast growth factor combination enhances periodontal regeneration in intrabony defects in dogs. Dent Mater J 28: 162-169.

18) O'Leary TJ, Drake RB, Naylor JE (1972) The plaque control record. J Periodontol 43:38.

19) Papapanou P, Sanz M, Buduneli N, Dietrich T, Feres M, Fine DH, Flemmig TF, Garcia R, Giannobile WV, Graziani F, Greenwell H, Herrera D, Kao RT, Kebschull M, Kinane DF, Kirkwood KL, Kocher T, Kornman KS, Kumar PS, Loos BG, Machtei E, Meng H, Mombelli A, Needleman I, Offenbacher S, Seymour GJ, Teles R, Tonetti MS (2018) Periodontitis: 
Consensus report of workgroup 2 of the 2017 World Workshop on the Classification of Periodontal and PeriImplant Diseases and Conditions. J Clin Periodontol 13:S162-S170.

20) Reynolds MA, Kao RT, Nares S, Camargo PM, Caton JG, Clem D S, Fiorellini JP, Geisinger ML, Millis MP, Nevins ML, Rosen PS (2015) Periodontal regeneration-intrabony defects: practical applications from the AAP regeneration workshop. Clinical Advances in Periodontics 5:21-29.

21) Saito A, Bizenjima T, Takeuchi T, Suzuki E, Sato M, Yoshikawa K, Kitamura Y, Matsugami D, Aoki H, Kita D, Imamura K, Irokawa D, Seshima F, Tomita S (2019) Treatment of intrabony periodontal defects using rhFGF-2 in combination with deproteinized bovine bone mineral or rhFGF-2 alone: A 6-month randomized controlled trial.J Clin Periodontol 46:332-341.

22) Saito A, Hosaka Y, Kikuchi M, Akamatsu M, Fukaya C, Matsumoto S, Ueshima F, Hayakawa H, Fujinami K, Nakagawa T (2010) Effect of initial periodontal therapy on oral healthrelated quality of life in patients with peri- odontitis in Japan. J Periodontol 81: 1001-1009.

23) Takayama S, Murakami S, Shimabukuro Y, Kitamura M, Okada H (2001) Periodontal regeneration by FGF-2 (bFGF) in primate models. J Dent Res 80:2075-2079.

24) Wennström JL, Tomasi C, Bertelle A, Dellasega E (2005) Full-mouth ultrasonic debridement versus quadrant scaling and root planing as an initial approach in the treatment of chronic periodontitis. J Clin Periodontol 32:851-859.

25) Zucchelli G, Amore C, Montebugnoli L, De Sanctis M (2003) Enamel matrix proteins and bovine porous bone mineral in the treatment of intrabony defects: a comparative controlled clinical trial. J Periodontol 74:1725-1735.

Correspondence:

Dr. Takahiro Bizenjima

Tokyo Dental College Chiba Dental

Center,

1-2-2 Masago, Mihama-ku, Chiba

261-8502, Japan

Email: bizenjimatakahiro@tdc.ac.jp 